\title{
Testing Paecilomyces lilacinus, diatomaceous earth and Azadirachta indica alone and in combination against cotton aphid (Aphis gossypii Glover) (Insecta: Homoptera: Aphididae)
}

\author{
Waqas Wakil ${ }^{1 \star}$, M. Usman Ghazanfar ${ }^{2}$, Yong Jung Kwon ${ }^{3}$, Ehsan Ullah ${ }^{4}$, Shamas-ul-Islam ${ }^{1}$ and \\ Kashif Ali ${ }^{1}$
}

\footnotetext{
${ }^{1}$ Department of Agricultural Entomology, University of Agriculture, Faisalabad, Pakistan.

${ }^{2}$ Department of Plant Pathology, College of Agriculture, University of Sargodha, Pakistan.

${ }^{3}$ School of Applied Biology and Chemistry, Kyungpook National University, Daegu, Korea.

${ }^{4}$ Department of Agronomy, University of Agriculture, Faisalabad, Pakistan.
}

Accepted 17 November, 2011

\begin{abstract}
The efficacy of Paecilomyces lilacinus (Thom.) Samson $\left(2.3 \times 10^{9}\right.$ conidia $\left.\mathrm{ml}^{-1}\right)$, Azadirachta indica (10 $\left.\mathrm{mlL}^{-1}\right)$ and the formulation of diatomaceous earth (PyriSec) $\left(3 \mathrm{gL}^{-1}\right)$ was tested for the control of cotton aphid (Aphis gossypii Glover) (Insecta: Homoptera: Aphididae) both under laboratory and semi-natural conditions. All the tested treatments gave significant control of aphid; however, $P$. lilacinus in combination with Neem showed the best control of aphids in detached leaf bioassay and semi-natural conditions. The applications of $P$. lilacinus and DE showed weak knock down effect on the insect pest. Furthermore, an increasing trend in mortality of aphids was observed in all the treatments with an increase in the time intervals. The results of the study clearly indicated that the $P$. lilacinus may give effective control of the aphids in combination with other eco-friendly control practices.
\end{abstract}

Key words: Paecilomyces lilacinus, diatomaceous earth, Azadirachta indica, aphid, cotton, insecticidal efficacy.

\section{INTRODUCTION}

Cotton (Gossypium hirsutum L.) is attacked by 1326 species of insects and mites that cause severe quantitative and qualitative losses. Among these, aphids and thrips are considered to be the most important insect pests causing 30 to $40 \%$ losses at its growing stage (Naqvi, 1976). The cotton aphid Aphis gossypii Glover (Insecta: Homoptera: Aphididae) is one of the most common species found on cotton, and is usually present on abaxial surface of leaves. It feeds on phloem, sucks cell sap from leaves and young shoots resulted in distortion, curling, wilting and some time premature defoliation of leaves, that in turn causes reduction of yield

\footnotetext{
*Corresponding author: E-mail: arid1972@yahoo.com.
}

both qualitatively and quantitatively. The secretions of honey dew allows associated fungi to grow that causes more than 50 types of diseases in plants due to transmission of viruses (Santos et al., 2004).

Many control strategies for insect pests of cotton have been documented; however, farmer's heavy reliance on pesticides to save the crop from pests resulted in the development of resistance in insects (Hajek and Leger, 1994). The regular and indiscriminate use is another reason of development of resistance in cotton aphid against traditional insecticide like deltamethrin, fenvalerate, monocrotophos, parathion, dimethoate, methomyl and aldicarb (Guilin et al., 1997).

Naturally occurring entomopathogenic fungi (EPFs) considered one of the best alternative to existing chemicals (Hajek and Leger, 1994) and these pathogens 
are found naturally attacking on number of pests (Wraight et al., 2000; Wakil and Ghazanfar, 2010; Riasat et al., 2011). Entomopathogenic fungi such as Lecanicillium sp. (Jung et al., 2006), Beauveria bassiana (Quesada et al., 2006; Wakil et al., 2011a), Metarhizium anisopliae (Wright et al., 2004), Paecilomyces (Shia and Feng, 2004) and Nomuraea rileyi (Devi et al., 2003; Wakil et al., $2011 \mathrm{~b}$ ) are being used for the control of aphids and other insect pests.

Diatomaceous earths are naturally occurring substances which consists of fossilized skeleton of unicellular diatoms and algae. They possess the high oil absorbing capacity and proved as insecticide (Athanassiou and Kavallieratos, 2005; Athanassiou et al., 2009). (Azadirachta indica A. Juss. (L.)) neem belong to family Meliacea is considered as safer bio-pesticide both in conventional and organic agriculture (Koul et al., 1990; Cross et al., 2007). The growth of various insect pests may be altered by the use of oil extracts of seeds and water and ethanol extracts (Montes-Molina et al., 2008). Azadirachtin is one of the potent active ingredients which affect the physiology and the behavior of the various insect pests, mites and nematodes (Ahmed and Grainge, 1985; Smirle et al., 1996; Dhar et al., 1998; Schaaf et al., 2000). Hence, this project was designed to evaluate the insecticidal efficacy of $P$. lilacinus, $A$. indica (Neem) and diatomaceous earth alone and in combination to scrutinize the synergistic interaction against cotton aphid both under laboratory and semi-natural conditions.

\section{MATERIALS AND METHODS}

\section{Rearing of A. gossypii}

A starter colony of aphid was obtained from the fields of Entomological research area and were maintained in the IPM Laboratory, Department of Agri. Entomology, University of Agriculture, Faisalabad, Pakistan on potted cotton plants at room temperature $\left(24 \pm 1^{\circ} \mathrm{C}\right)$ and $16 \mathrm{~L}: 8 \mathrm{D}$ photoperiod. To synchronize the aphid ages to be used in the bioassays, a group of adult aphids was placed on $8 \mathrm{~cm}$ cotton leaf disc in Petri plate containing moistened filter paper and held for $20 \mathrm{~h}$. Adults were removed from the leaf discs and the progeny was then transferred to a potted cotton plant covered with fabric sleeve where they were incubated for 6 days in an insect rearing room before use in bioassays.

\section{Mass-culturing of $\boldsymbol{P}$. lilacinus}

The culture of $P$. lilacinus (Thoms.) Samson was provided by the Institute of Plant Protection, Poznan, Poland. It was firstly isolated from the eggs of sugar beet cyst nematode (Heterodera schachtii Schmidt) collected from the fields near Toren. The fungus was subcultured on Potato Dextrose Agar (Difco TM, Becton Dickinson and Company, USA) with the help of sterilized bacteriological loop and the plates were closed by Parafilm at $25 \pm 1{ }^{\circ} \mathrm{C}$ for 14 days. The conidia were harvested using sterilized rubber loop attached to $1 \mathrm{ml}$ borosilicate pipette at the angle of $45^{\circ}$. The scraped material was shifted into sterilized Petri plates and stored at $4^{\circ} \mathrm{C}$ in refrigerator. The harvested fungal conidia were incorporated in to sterile $0.05 \%$
Tween-80 solution and the material was stirred for complete homogeneity. The serial dilutions were prepared and the number of conidia was measured to achieve the $2.3 \times 10^{9}$ conidia $\mathrm{ml}^{-1}$ concentration under haemocytometer.

\section{DE and $A$. indica extract}

PyriSec ${ }^{\circledR}$ is a mixture of $25 \%$ pyrethrum, $3.1 \%$ pipronylbutaoxide and $97.5 \%$ diatomaceous earth (SilicoSec). Fresh leaves and seeds of Neem were collected from the botanical garden of the University of Agriculture, Faisalabad, Pakistan, and washed with distilled water to remove the dust and other contaminants. They were kept in a muslin cloth for 30 min to drain water. The seeds and leaves were crushed and grinded in the electrical grinder with 100 $\mathrm{ml}$ of distilled water to make the paste which was again kept for 72 h. The distilled water was again added to make the solution which was passed through muslin cloth and the extract was stored at $4^{\circ} \mathrm{C}$ in refrigerator in vials sealed with air tight lid.

\section{Detached leaf-disc bioassay}

The detached leaf disc method was adopted and the healthy cotton leaf discs $(5 \mathrm{~cm}$ in diameter) were placed in $9 \mathrm{~cm}$ Petri-plates. The leaf discs were dipped for $5 \mathrm{~s}$ in $P$. lilacinus conidial suspension $\left(2.3 \times 10^{9}\right.$ conidia $\left.\mathrm{l}^{-1}\right)$ for alone and combined treatments. The leaf discs were air-dried in the clean bench and at room temperature for $1 \mathrm{~h}$. The Neem extract $\left(10 \mathrm{~mL}^{-1}\right)$ was mixed with PyriSec $\left(3 \mathrm{gL}^{-1}\right)$ and sprayed on the leaf discs with hand sprayer. The leaf discs treated with $0.05 \%$ Tween- 80 served as control. Each Petri plate with leaf discs was provided with moistened filter paper on the bottom with $1 \mathrm{~cm}$ hole on lid covered with fine mesh for aeration. Thirty cotton aphid were released in each Petri plate using camel's hair brush and the Petri plates were then placed in growth chamber maintained at $25 \pm 1{ }^{\circ} \mathrm{C}$ and $>70 \%$ relative humidity at $16 \mathrm{~L}: 8 \mathrm{D}$ photoperiod. The data for mortality was recorded after $2,4,6,8$ and 10 days intervals. Each treatment and bioassay was repeated independently for three times. Dead individuals were removed and considered as dead if they did not move when prodded with needle.

\section{Semi-natural conditions bioassay}

The cotton plants of var. CIM-496 due to its good yield potential and resistant to CLCuV were grown in pots under semi-natural conditions. The experiments were conducted in the screen house of the Department of Agricultural Entomology, University of Agriculture Faisalabad, Pakistan. Thirty newly reared adults of cotton aphid were released on the leaves of each potted cotton plant using camel hair brush and allowed to settle for 3 to $4 \mathrm{~h}$. The above said treatments were replicated three times (6-plants per replicate) and both sides of leaves of each plant were sprayed with the help of an automizer. The plants sprayed with $0.05 \%$ Tween- 80 served as control. The plants were air dried at normal atmospheric conditions for $30 \mathrm{~min}$. The potted plants were covered with fabric sleeve to avoid the movement of adults from one plant to other. The mortality data were recorded after 2, 4, 6, 8 and 10 day. The bioassays were repeated for three times and the individuals considered dead if they did not move when prodded with needle.

\section{Statistical analysis}

The mortality data were subjected to statistical analysis using the Minitab 2002 (Minitab, Software Inc., Northampton, MA) and the means were separated by Tukey-Kramer test at $P=0.05$ (Sokal and Rohlf, 1995). 
Table 1. ANOVA parameters for the mortality of $A$. gossypii (total $d f=119$ )

\begin{tabular}{lcccccc}
\hline \multirow{2}{*}{ Source of variance } & \multirow{2}{*}{ df } & \multicolumn{2}{c}{ Leaf disc bioassay } & & \multicolumn{2}{c}{ Semi-natural condition } \\
\cline { 3 - 4 } \cline { 6 - 7 } & & $\mathbf{F}$ & $\mathbf{P}$ & & $\mathbf{F}$ & $\mathbf{P}$ \\
\hline Replications & 3 & 2.81 & 0.044 & & 4.24 & 0.008 \\
Days & 4 & 7080.42 & $<0.001$ & & 7052.61 & $<0.001$ \\
Doses & 5 & 1.204 & $<0.001$ & & 1.104 & $<0.001$ \\
Days $x$ doses & 20 & 288.78 & $<0.001$ & & 267.98 & $<0.001$ \\
\hline
\end{tabular}

\section{RESULTS}

\section{Mortality of A. gossypii with detached leaf-disc bioassay}

The data regarding the effect of different treatments on the aphid in cotton at different intervals showed highly significant difference (Table 1). The maximum mortality $37.67 \%$ of aphid was recorded where $P$. lilacinus and Neem was combined. The lowest effect on aphid was recorded 14.50 and $19.25 \%$ in $P$. lilacinus and DE, respectively (Figure 1a). $P$. lilacinus in combination with Neem at 4 days resulted to maximum $(43.85 \%)$ mortality of aphid and the minimum (22.16\%) mortality was observed in P. lilacinus. However, DE exhibited $25.16 \%$ mortality while in combination with $P$. lilacinus, it reaches $35.54 \%$ mortality (Figure $1 b$ ).

The effect of combination of $P$. lilacinus and Neem was observed to be maximum mortality of aphid at 6 days interval, while DE alone showed minimum effect with $29.85 \%$ mortality (Figure 1c). The maximum (61.46\%) mortality at 8 days interval was recorded in discs treated with $P$. lilacinus and Neem compared with $54.83 \%$ mortality of $P$. lilacinus combined with $\mathrm{DE}$. The minimum $35.83 \%$ mortality was recorded in DE treatment (Figure $1 \mathrm{~d})$. The mortality $(82.89 \%)$ was maximum where $P$. lilacinus and Neem was combined, however, the minimum $(46.44 \%)$ as noted with sole application of $P$. lilacinus (Figure 1e). It is observed that the effectiveness of all the treatments showed an increasing trend up to 10 days of post application.

\section{Mortality of A. gossypii with semi-natural conditions bioassay}

The effect of $P$. lilacinus, Neem and DE on the population of aphid under semi natural conditions revealed significant difference among treatments (Table 1). The maximum $(34.68 \%)$ mortality was recorded in $P$. lilacinus and Neem at 2 days interval (Figure 2a). The minimum (12.5 and $15.54 \%$ ) mortality of aphid was observed with $P$. lilacinus and DE treatment, respectively. $P$. lilacinus and Neem revealed maximum $(41.56 \%)$ mortality of aphid which was significantly different from all other treatments (Figure 2b). The minimum (22.35\%) mortality was recorded in DE; however, $P$. lilacinus with $\mathrm{DE}$ and Neem exhibited 31.89 and $29.57 \%$ mortality of aphid, respectively. The application of $P$. lilacinus + Neem resulted in maximum $(49.50 \%)$ mortality which was significantly different with $P$. lilacinus + DE (Figure 2c). The application of Neem showed $37.23 \%$ mortality however non significant differences were noted between $P$. lilacinus and DE application with 28.06 and $26.68 \%$, respectively.

The application of $P$. lilacinus and Neem showed maximum $(57.35 \%)$ mortality, however, DE alone has minimum $32.39 \%$ mortality of aphid which showed significant difference with 44.61 and $40.67 \%$ mortality with alone application of Neem and $P$. lilacinus, respectively (Figure $2 \mathrm{~d}$ ). The highest mortality $(71.45 \%)$ was noted with the application of $P$. lilacinus and Neem, while DE and Neem showed 41.23 and $51.32 \%$ mortality, respectively. The intermediate response $(58.34 \%)$ was showed by $P$. lilacinus (Figure 2e).

\section{DISCUSSION}

The results of our study clearly indicated that the application of $P$. lilacinus in combination with Neem showed maximum mortality and proved good potential for the control of cotton aphid. Furthermore, $P$. lilacinus in combination with DE showed better results for the control of this notorious insect pest. The present findings are in partial conformity with Santos et al. (2004) who reported that Neem seed powder in highest concentration (1410.0 $\mathrm{mg} 100 \mathrm{ml}^{-1}$ ) was efficient against $A$. gossypii on cotton causing nymph mortality and reducing their survival period and fecundity. Similarly, Stark and Rangus (1994) reported that the molting process of Acyrthosiphon pisum (Harris) nymphs was totally interrupted at two concentrations (80 and $100 \mathrm{mg}$ azadirachtin $\mathrm{L}^{-1}$ ). The nymphs of Toxoptera citricida (Kirkaldy) reared on citrus seedlings which were sprayed with Neemix showed the similar response with 0.4 molts (Tang et. al., 2002). The active ingredient (Azadirachtin) actually causes an interruption in ecdysone and juvenile hormone in the insect hemolymph which ultimately affects molting, metamorphosis and reproduction (Mordue and Nisbet, 2000). The pea aphid population was reduced after 3 
1a

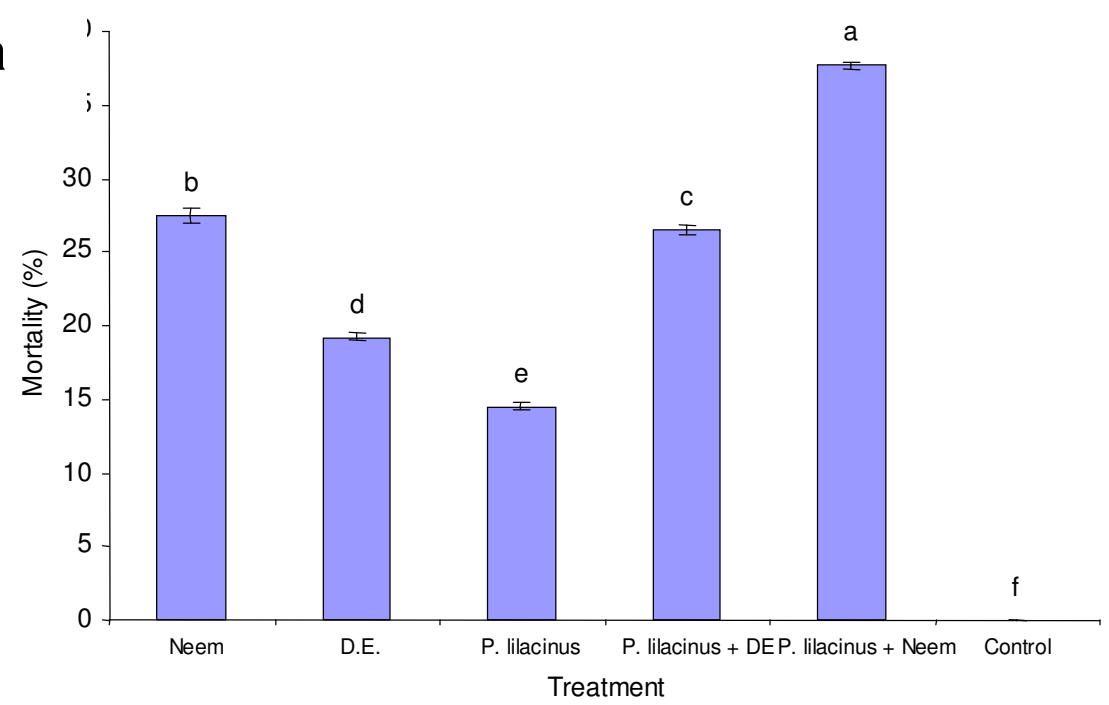

$1 \mathrm{c}$

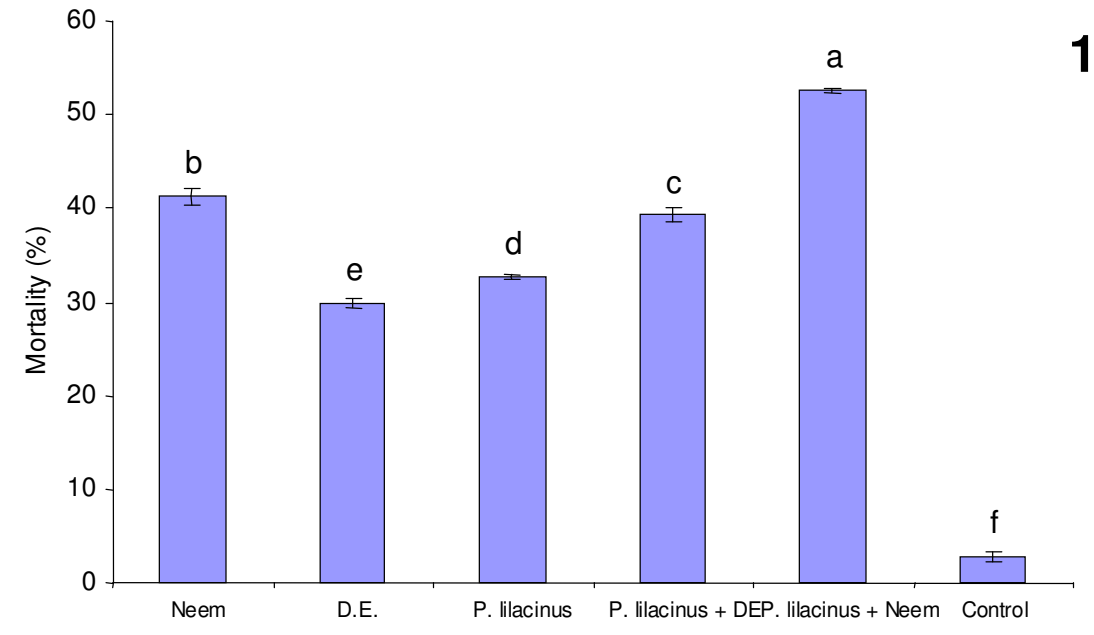

$1 b$

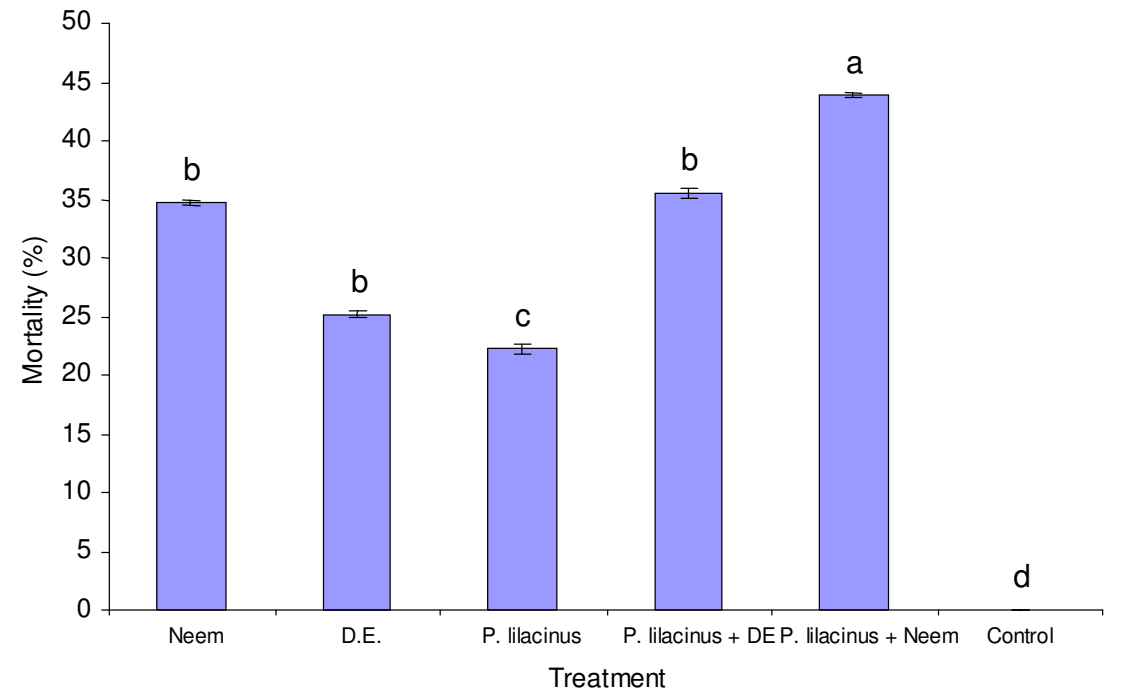

1d

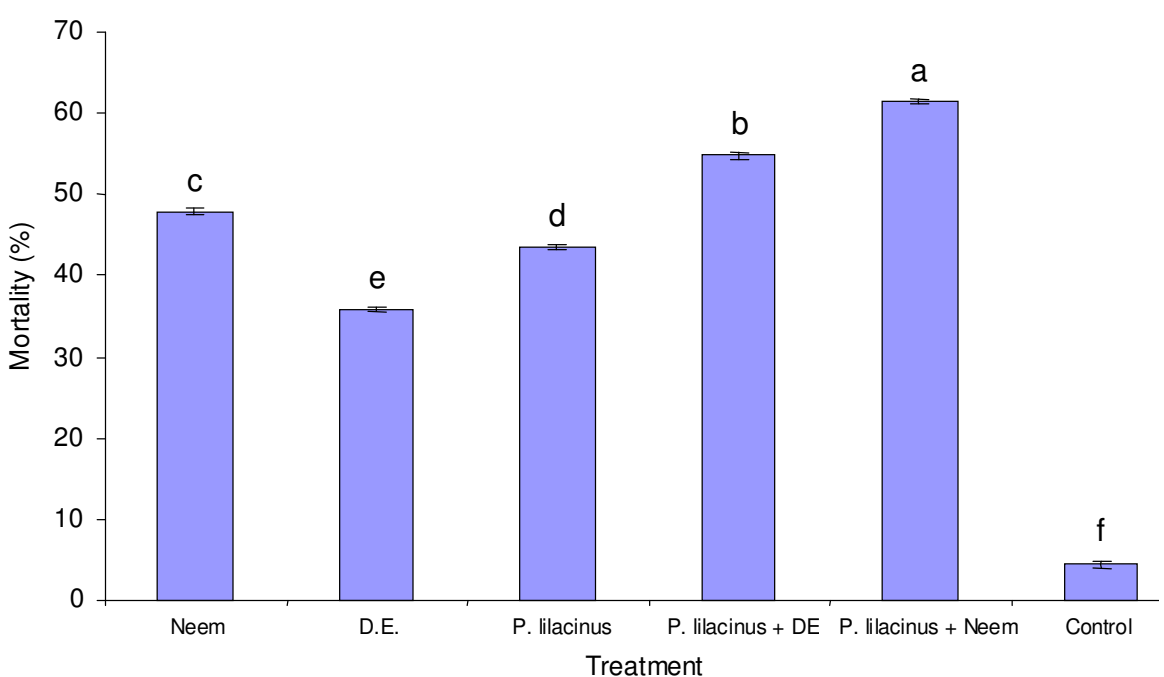

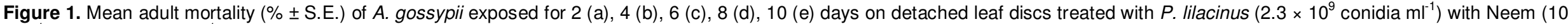
$\left.\mathrm{mlL}^{-1}\right)$ and PyriSec $\left(3 \mathrm{gL}^{-1}\right)$ (means followed by the same letters are not significantly different at $P=0.05$ ). 


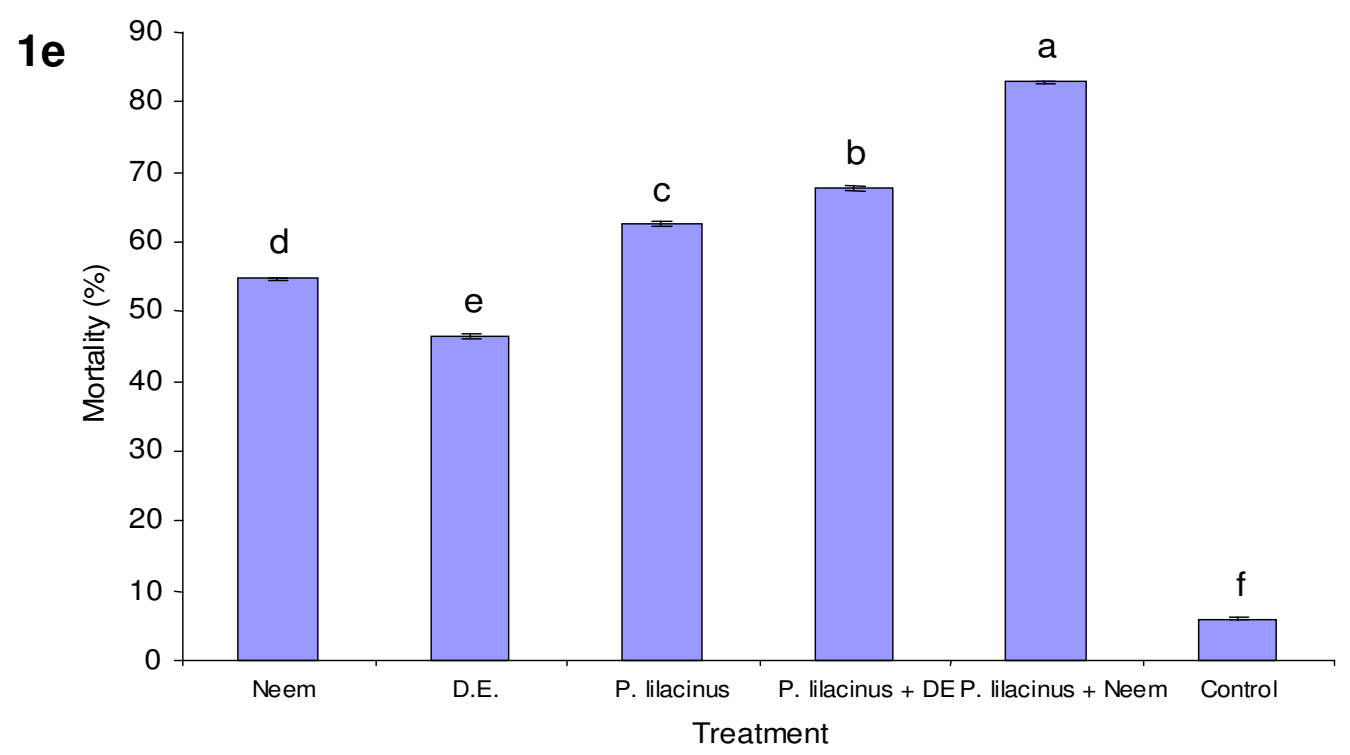

Figure 1. Contd.
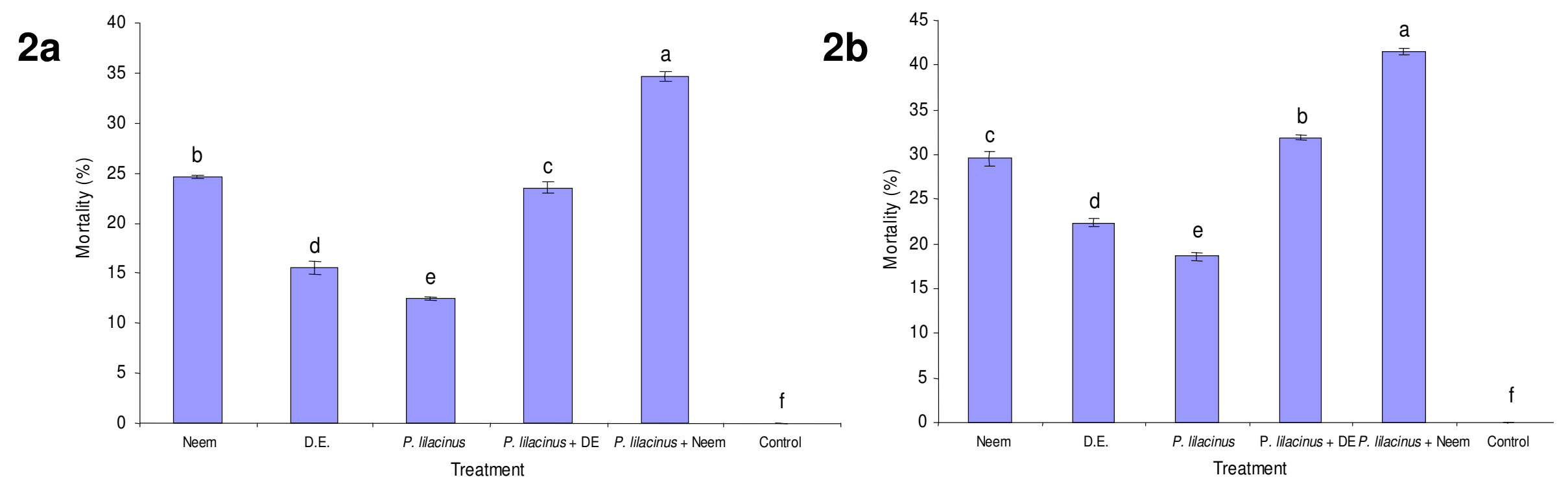

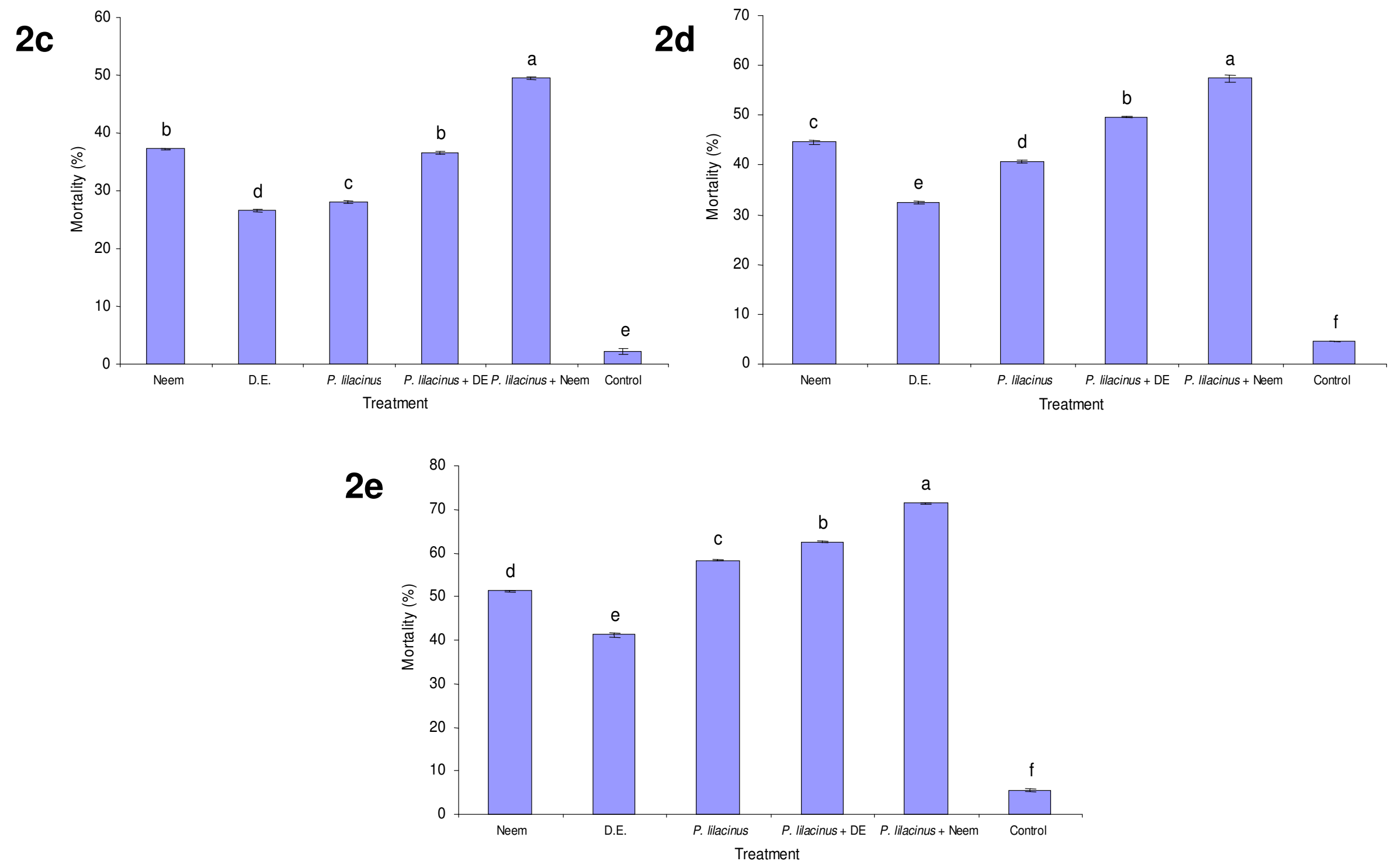

Figure 2. Mean adult mortality (\% \pm S.E.) of $A$. gossypii exposed for 2 (a), 4 (b), 6 (c), 8 (d), 10 (e) days on cotton under semi-natural conditions treated with $P$. lilacinus $\left(2.3 \times 10^{9}\right.$ conidia $\mathrm{ml}^{-1}$ ) with Neem $\left(10 \mathrm{~mL} \mathrm{~L}^{-1}\right)$ and PyriSec $\left(3 \mathrm{gL}^{-1}\right)$ (means followed by the same letters are not significantly different at $\left.P=0.05\right)$. 
days post treatment up to $50 \%$ with the application of azadirachtin compound (Sadeghi et al., 2009). The Neem may also be integrated with DE which presented good results (El-Wakeil and Saleh, 2009) as they reported the combination of Neem with diato-maceous earth against Myzus persicae (Sulzer) with best control and no impact on the associated natural enemies.

The entomopathogenic fungi are extensively evaluated for the control of aphid on various crops as Steinkraus (1999) controlled cotton aphid by applying aerial conidia of Neozygites fresenii. We observed that $P$. lilacinus was very efficient in controlling aphid both under laboratory and semi-natural conditions even when applied singly or combined with Neem or diatomaceous earth. The significant control of aphid on cotton seedlings was also observed by the application of Colletotrichum orbiculare (Russo et al., 1997) which is in line with the present work. Similarly, Kim et al., (2008) tested the effectiveness of the commercial formulation of Lecanicillium longisporum (Vertalec) for the control of cotton aphid and reported the noteworthy reduction in the aphid number compared to untreated control. The pathogenicity of different isolates of Beauveria bassiana, Paecilomyces spp. and Lecanicillium attenuatum was evaluated against cotton aphid (Kim and Kim, 2008) where mortality reaches up to $100 \%$ after 5 days when treated either with conidia or blasto-spores of the fungus.

\section{Conclusion}

In the light of the present study it is concluded that the entomopathogenic fungi may gave better results by replacing the traditional residual insecticides for the control of field insect pests. They may also be triggered by the combination of other safe products like Neem and diatomaceous earth but more research is needed to incorporate them in successful IPM protocols.

\section{ACKNOWLEDGEMENTS}

The authors are greatly indebted to the Institute of Plant Protection, Poznan, Poland, for providing the isolate of $P$. lilacinus. The research was supported by Higher Education Commission, Islamabad, Pakistan, under the Indigenous fellowship program.

\section{REFERENCES}

Ahmed S, Grainge M (1985). The use of indigenous plant resources in rural development: potential of the neem tree. Int. J. Dev. Technol. 3: 123-130.

Athanassiou CG, Arthur FH, Opit GP, Throne JE (2009). Insecticidal effect of diatomaceous earth against three species of stored-product Psocids on maize, rice, and wheat. J. Econ. Entomol. 102: 16731680.

Athanassiou CG, Kavallieratos NG (2005). Insecticidal effect and adherence of PyriSec ${ }^{\circledR}$ in different grain commodities. Crop Prot. 24:
703-710.

Cross JV, Cubison S, Harris A, Harrington R (2007). Autumn control of rosy apple aphid Dysaphis plantaginea (Passerini) with aphicides. Crop Prot. 26: 1140-1149.

Devi PSV, Prasad YG, Chowdary YGA, Rao DM, Balakrishnan LK (2003). Identification of virulent isolates of the entomopathogenic fungus Nomuraea rileyi (F) Samson for the management of Helicoverpa armigera and Spodoptera litura. Mycopath. 156: 365373.

Dhar R, Zhang K, Talwar GP, Garg S, Kumar N (1998). Inhibition of the growth and development of asexual and sexual stages of drugsensitive resistant strains of the human malaria parasite Plasmodium falciparum by neem (Azadirachta indica) fractions. J. Ethnopharmacol. 61: 3-39.

El-Wakeil NE, Saleh SA (2009). Effects of neem and diatomaceous earth against Myzus persicae and associated predators in addition to indirect effects on artichoke growth and yield parameters. Arch. Phytopathol. Plant Prot. 42: 1132-1143.

Guilin C, Runzxi L, Mingjiang H, Kefu X, Shiju J (1997). Comparison of the cotton aphid resistance level between Xinjiang and Shandong populations. Res. Pest Manage. Newslett. 9: 10-12.

Hajek AE, Leger ST (1994). Interaction between fungal pathogen and insect hosts. Ann. Rev. Entomol. 39: 293-322.

Jung HS, Lee HB, Kim K, Lee EY (2006). Selection of Lecancillium strains for aphid (Myzus persicae) control. Korean J. Mycol. 34: 112118.

Kim JJ, Goettel MS, Gillespie DR (2008). Evaluation of Lecanicillium longisporum, Vertalec for simultaneous suppression of cotton aphid, Aphis gossypii, and cucumber powdery mildew, Sphaerotheca fuliginea on potted cucumbers. Biol. Control, 45: 404-409.

Kim JJ, Kim KC (2008). Selection of a highly virulent isolate of Lecanicillium attenuatum against cotton aphid. J. Asia. Pacific Entomol. 11: 1-4.

Koul O, Isman MB, Ketkar CM (1990). Properties and uses of neem (Azadirachta indica). Can. J. Bot. 68: 1-11.

Montes-Molina JA, Luna-Guido ML, Espinoza-Paz N, Govaerts B, Gutierrez-Miceli FA, Dendooven L (2008). Are extracts of neem Azadirachta indica A. Juss. (L.) and Gliricidia sepium (Jacquin) an alternative to control pests on maize (Zea mays L.). Crop Prot. 27: 763-774.

Mordue AJ, Nisbet AJ (2000). Azadirachtin from the neem tree Azadirachta indica: its actions against insects. Anais da Sociedade Entomológica do Brasil. 29: 615-632.

Naqvi KM (1976). Crop protections to boost up the cotton production. Seminar organized by ESSO, Fert. Co. Ltd. Pakistan. p. 74.

Quesada ME, Maranhao EA, García PV, Álvarez CS (2006). Selection of Beauveria bassiana isolates for control of the whiteflies Bemisia tabaci and Trialeurodes vaporariorum on the basis of their virulence, thermal requirements, and toxicogenic activity. Biol. Control. 36: 274287.

Riasat T, Wakil W, Ashfaq M, Sahi ST (2011). Effect of Beauveria bassiana mixed with diatomaceous earth on mortality, mycosis and sporulation of Rhyzopertha dominica on stored wheat. Phytoparasitica. DOI: 10.1007/s12600-011-0164-6.; Published Online: 11.05.2011.

Russo VM, Russo BM, Petrs M, Veazie PP, Cartwright B (1997). Interaction of Colletotrichum orbiculare with thrips and aphid feeding on watermelon seedlings. Crop Prot. 16: 581-584.

Sadeghi A, Van Damme EJM, Smagghe G (2009). Evaluation of the susceptibility of the pea aphid Acyrthosiphon pisum to a selection of novel biorational insecticides using an artificial diet. J. Insect Sci. 9: 65; available online: insectscience.org/9.65.

Samtos TM, Costa NP, Torres AL, Junior ALC (2011). Effect of mean extract on the cotton aphid.Pesq. Agropec.Bras. 39(11): 1071-1076.

Schaaf $O$, Jarvis AP, Van der Esch SA, Giagnavoco G, Oldham NJ (2000). Rapid and sensitive analysis of azadirachtin and related triterpenoids from neem (Azadirachta indica) by high performance liquid chromatography-atmospheric pressure chemical ionization mass spectrometry. J. Chromatogr. 886: 89-97.

Shia WB, Feng MG (2004). Lethal effect of Beauveria bassiana, Metarhizium anisopliae, and Paecilomyces fumosoroseus on the 
eggs of Tetranychus cinnabarinus (Acari: Tetranychidae) with a description of a mite egg bioassay system. Biol. Control. 30: 165-173.

Smirle MJ, Lowery DT, Zurowski CL (1996). Influence of neem oil on detoxication on enzyme activity in the obliquebanded leafroller (Choristoneura rosaceana). Pestic. Biochem. Phys. 56: 220-230.

Sokal RR, Rohlf FJ (1995). Biometry, 3rd Ed. Freedman and Company, New York.

Stark JD, Rangus TM (1994). Lethal and sublethal effects of the neem insecticide formulation, 'Margosan-O', on the pea aphid. Pesticide Sci. 41: 155-160.

Steinkraus DC, Boys GO, Rosenheim GA (1999). Classical biological control of Aphis gossypii (Homoptera: Aphididae) with Neozygites fresenii (Entomophthorales: Neozygitaceae) in California cotton. Biol. Control. 25: 297-304.

Tang YQ, Weathersbee III AA, Mayer RT (2002). Effect of neem extract on the brown citrus aphid (Homoptera: Aphididae) and its parasitoid Lysiphlebus testaceipes (Hymenoptera: Aphididae). Environ. Entomol. 31: 172-176.

Wakil W, Ashfaq M, Ghazanfar MU, Riasat T (2010). Susceptibility of stored-product insects to enhanced diatomaceous earth. J. Stored Prod. Res. 46: 248-249.

Wakil W, Ghazanfar MU (2010). Entomopathogenic fungus as a biological control agent against Rhyzopertha dominica $\mathrm{F}$. (Coleoptera: Bostrychidae) on stored wheat. Arch. Phytopathol. Plant Prot. 43: 1236-1242.
Wakil W, Riasat T, Ghazanfar MU, Kwon YJ, Shaheen FA (2011a). Aptness of Beauveria bassiana and enhanced diatomaceous earth (DEBBM) for control of Rhyzopertha dominica F. Entomol. Res. doi: 10.1111/j.1748-5967.2011.00342.x.

Wakil W, Ghazanfar MU, Kwan YJ, Shamas-ul-Islamc, Alik (2011b). Toxicity of Paecilomyces lilacimus blended with mom-comventional agents to control cotton thrips (Thrips tabaci limd.) (Imsecta; Thysanoptera: thripidac). Afr.J Microbiol. Res., DOI: 10.5897/AJMR11.859 (Im Press)

Wraight SP, Carruthers RI, Bradley CA, Jaronski ST, Lacey LA, Wood P, Wraight SG (2000). Evaluation of the entomopathogenic fungi Beauveria bassiana and Paecilomyces fumosoroseus for microbial control of the silver leaf whitefly Bemisia argentifolii. Biol. Control. 17: 203-217.

Wright C, Brooks A, Wall R (2004). Toxicity of the entomopathogenic fungus, Metarhizium anisopliae (Deuteromycotina: Hyphomycetes) to adult females of the blowfly Lucilia sericata (Diptera: Calliphoridae). Pest Manage. Sci. 60: 639-644. 